\title{
An Application of the Ramsey Number in the Electricity Pricing
}

\author{
Haiming Li, Jia He \\ School of Computer and Information Engineering, Shanghai University of Electric Power, Shanghai, China \\ Email: zjxulhm@163.com
}

How to cite this paper: Li, H.M. and He, J. (2016) An Application of the Ramsey Number in the Electricity Pricing. Journal of Computer and Communications, 4, 89-97. http://dx.doi.org/10.4236/jcc.2016.414007

Received: October 18, 2016

Accepted: November 25, 2016

Published: November 28, 2016

Copyright () 2016 by authors and Scientific Research Publishing Inc. This work is licensed under the Creative Commons Attribution International License (CC BY 4.0).

http://creativecommons.org/licenses/by/4.0/

\begin{abstract}
The Ramsey number is a foundational result in combinatorics. This article will introduce Ramsey number with the method of graph theory, and the Ramsey pricing theory is applied to the sales price and study of cross subsidy. Based on the status of our sales price and cross subsidy, Ramsey pricing methods theoretically guide adjustment thoughts of sales price and solve the practical problems in our life.
\end{abstract}

\section{Keywords}

Ramsey Number, Graph Theory, Ramsey Pricing Theory

\section{Introduction}

\subsection{The Background of Ramsey Number}

The definition of Ramsey number was first proposed by the British mathematician Ramsey in 1928. Since 1930, a large number of scholars made a thorough study of the Ramsey number, but now the exact value of the Ramsey number having been developed by people remains low. It is described in any discrete structure, as long as the "structure" is sufficiently large, there must be a particular sub-section. This definition was subsequently developed into Ramsey theory by Graham, Rothschild and Spencer [1]. Ramsey number of graphs is the promotion of Ramsey number theory. It has been much attention as a well-known problem in graph theory, and its research in graph theory has been rapidly developed. Graphic Ramsey numbers $R\left(G_{1}, G_{2}\right)$ refer to that for a given graph $G_{1}, G_{2}$, there is a minimum positive integer $n$, such that for an arbitrary order $n$ in graph $G, G_{1} \subseteq G$, or the complement graph of $G$ contains $G_{2}$ [2]. Ramsey theory reveals an important philosophical thought in mathematical: the disorder is relative, to a certain extent, some orderly structure must appear. Ramsey number is defined as the minimum value of the amount in order to ensure that such a 
structure must appear. Some people think that mathematical induction and Ramsey theory are the two branches of mathematics. Mathematical induction is an approach that infinity scenario can be inferred from the limited case, while Ramsey theory is the study that a limited number of exceptions is found from the infinite case. Ramsey number corresponds to the minimum groundbreaking number of mathematical induction. The groundbreaking number, which was needed by mathematical induction, is usually easy to find, but the exact Ramsey number is difficult to determine generally [3].

\subsection{Basic Concepts of Graph Theory [4]}

Graph: Graph $G$ refers to an ordered triple $\left(V(G), E(G), \varphi_{G}\right), V(G)$ is nonvoid set of vertices, $E(G)$ is the link between the edge set of vertices, $\varphi_{G}$ is the correlation function, which enables each edge of $G$ corresponds to the disordered pairs of vertex of $G$ (no dissimilarity). The number of vertices and edges of $G$ respectively represented by the symbol $V(G)$ and $d G(v)$, side with the $e\left(v_{i}, v_{j}\right)$. In the figure $G$ the degree of vertex $v$ and $d G(v)$ refers to the number of edges where $G$ is associated with $v$ and in the graph $G$ maximum and minimum of vertices are denoted as $\Delta(G)$ and $\delta(G)$.

Simple Graph: A simple graph is a diagram what has neither rings nor two links linking to the same pair of vertices.

Complete Graph: A complete graph is a simple undirected graph in which every pair of distinct vertices is connected by a unique edge. The complete graph on $n$ vertices is denoted by $K_{n}$.

Sub-graph: For a graph $G$ and $H$, if $V(H) \subseteq V(G), E(H) \subseteq E(G)$, and $\varphi_{H}$ is limit of $\varphi_{G}$ in $E(H)$, then graph $H$ is called sub-graph of graph $G$. If $H \subseteq G$, $H \neq G, \mathrm{H}$ is called the proper Sub-graph of $G$. Supposed that $V^{\prime}$ is a non-void set of $\mathrm{V}$, the sub-graph is composed of edge set that is based on $V^{\prime}$ as a vertex set and the whole edges with their two points in the $V^{\prime}$, and it is named sub-graph exported by $V^{\prime}$ of $G$, which is described as $G\left[V^{\prime}\right]$. The sub-graph $G\left[V / V^{\prime}\right]$ is described as $G-V^{\prime}$. Supposed that $E^{\prime}$ is non-void set of $E$, the sub-graph is composed of vertex set that is based on $E^{\prime}$ as a edge set and the endpoint of $E^{\prime}$ as vertex set, and it is called sub-graph exported by $E^{\prime}$ of $G$, which is described as $G\left[E^{\prime}\right]$. The sub-graph $G\left[E / E^{\prime}\right]$ exported is described as $G-E^{\prime}$.

\section{The Ramsey Number}

\subsection{The Introduction of Ramsey Problem}

Let's lead to Ramsey problem by a classic life example: six people together, there are at least three people either knowing each other or unknowing each other. If using graph theory to prove this problem, then we can represent these six individuals with six vertices A, B, C, D, E, F. Over these six vertices for the complete graph, if two people know each other connect the two vertices with a solid line, else with a dotted line.

Ramsey problem is equivalent to prove the edge of this complete graph with six vertices. With solid and broken lines be represented, there must be at least either one equi- 
lateral triangle with solid line, or one equilateral triangle with dotted line.

Take the point $A$ for instance, if we connect point $A$ and the other five vertices, there are five edges, each edge or as a solid line or a dotted line. According to the pigeonhole principle, at least three edges are the same line. Assume there are three edges are solid lines in Figure 1.

As shown, if set point $\mathrm{A}$ to point $\mathrm{B}, \mathrm{F}$ as dotted lines, to point $\mathrm{C}, \mathrm{D}, \mathrm{E}$ as the solid line, regardless of the connection lines of three endpoints $C, D, E$ are dotted or solid line, then it will meet Ramsey problem. If three connection lines are different, according to the pigeonhole principle, at least one is a solid line, assuming that a solid line of connection $\mathrm{C}$ and $\mathrm{E}$, the $\mathrm{ACE}$ can constitute an equilateral triangle with the solid line, and meet the Ramsey problem as well.

\subsection{The Basic Theory of Ramsey Number}

In the same way we can prove 9 or 10 individuals, either three people unknowing each other or four individuals knowing each other certainly. By discussing these examples, we can find some numbers are special, they can meet the Ramsey problem, which are Ramsey numbers a number of scholars have studied so far. It has not been able to accurately calculate Ramsey numbers with a formula, but we can still draw a conclusion: a pair of constants $a$ and $b$, corresponding to an integer $r$, such that among $\mathrm{r}$ individuals either a people know each other, or $b$ individuals un-know each other; either a strangers, or $b$ acquaintances, the minimum number of $r$ is denoted as $R(a, b)$, that is the complete graph with $R(a, b)$ vertices. With dotted and solid lines indicate, in any case there is at least: 1) a complete sub-graph with a vertices and solid lines, or a complete sub-graph with b vertices and dotted lines; 2 ) there is at least one complete graph with a vertices and dotted lines or a complete graph $\mathrm{b}$ vertices and solid lines. The two must have one set up, and R can be expressed as Ramsey number.

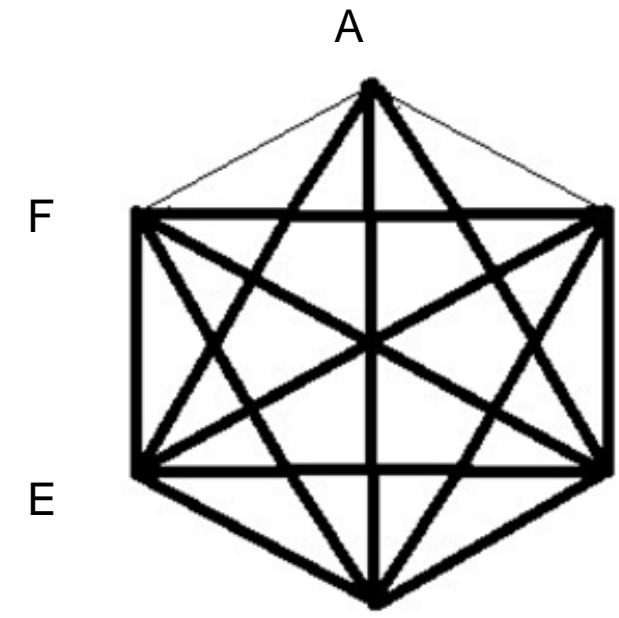

B

D

Figure 1. Ramsey problem. 
The above example can be transformed into the equation of the complete graph: $K_{6}, K_{3}, K_{3}$; By using Ramsey number $K_{9}, K_{3}, K_{4}$ is denoted as $R(3,3)=6$; $R(3,4)=9$. The Ramsey number which has been proven is shown in Table 1 [5].

\section{The Ramsey Pricing Theory}

Theory is to solve practical problems in our lives, then we will induce an example about how to apply Ramsey pricing method to solve the cross-subsidies sales price problem.

\subsection{The Introduction of the Sales Price Cross-Subsidies Problem}

In the 21st century, the economic construction in China has entered into an unprecedented period of rapid growth. Rapid economic development has led to a continued increase in the demand for electricity, which undoubtedly put forward newer and higher requirements to the power industry of our country. With the continuous advance of the power system reform, our country has achieved initial success in separation of plant and network, construction of power generation side market and other aspects. It has become a common concern that how to deepen the reform of the electricity power market. As we all know, a reasonable electricity price mechanism is one of the key factors to ensure the smooth progress of China's electric power market reform and to promote the sustainable and rapid development of power industry. Reasonable sales price can reflect the power supply and demand timely and effectively, at the same time it is advantageous to guide the user to use the electric power reasonably, and promote the optimization of electric power resources.

By the impact of the past planned economy, China's existing electricity price system has been unable to meet the requirements of the electricity market reform. In the traditional vertically integrated electric power industry management system, for economic development, social stability and other aspects, the government implement preferential

Table 1. Example of Ramsey numbers.

\begin{tabular}{|c|c|c|c|c|c|c|c|c|c|c|c|c|c|}
\hline$b^{a}$ & 3 & 4 & 5 & 6 & 7 & 8 & 9 & 10 & 11 & 12 & 13 & 14 & 15 \\
\hline \multirow{2}{*}{3} & \multirow{2}{*}{6} & \multirow{2}{*}{9} & \multirow{2}{*}{14} & \multirow{2}{*}{18} & \multirow{2}{*}{23} & \multirow{2}{*}{28} & \multirow{2}{*}{36} & 40 & 46 & 51 & 59 & 66 & 73 \\
\hline & & & & & & & & 43 & 51 & 60 & 69 & 78 & 89 \\
\hline \multirow{2}{*}{4} & & \multirow{2}{*}{18} & \multirow{2}{*}{25} & 35 & 49 & 53 & 69 & 80 & 96 & 106 & 118 & 129 & 134 \\
\hline & & & & 41 & 61 & 84 & 115 & 149 & 191 & 238 & 291 & 349 & 417 \\
\hline \multirow{2}{*}{5} & & & 43 & 58 & 80 & 95 & 114 & \multirow{2}{*}{442} & & & & & \\
\hline & & & 49 & 87 & 143 & 216 & 316 & & & & & & \\
\hline \multirow{2}{*}{6} & & & & 102 & 298 & 495 & 780 & 1171 & & & & & \\
\hline & & & & 165 & & & & & & & & & \\
\hline \multirow{2}{*}{7} & & & & & 205 & 1031 & 1713 & 2826 & & & & & \\
\hline & & & & & 540 & 1031 & 1713 & 2020 & & & & & \\
\hline \multirow{2}{*}{8} & & & & & & 1870 & 282 & 6090 & & & & & \\
\hline & & & & & & 1070 & 3583 & 0000 & & & & & \\
\hline \multirow{2}{*}{9} & & & & & & & & 565 & & & & & \\
\hline & & & & & & & 6625 & 12715 & & & & & \\
\hline 10 & & & & & & & & 23,854 & 798 & & & & \\
\hline
\end{tabular}


tariff for some types of users, then the current sales price cross-subsidies problem appears. From the perspective of long-term development, cross-subsidies would not only seriously hinder the effective competition in the electricity market of construction, but not conducive to the overall coordination development of the national economy and the realization of the whole social resources' optimization allocation. At present, China's electric power system reform has entered the stage of liberalizing the user's choice and constructing the sale market. The power system reform program the government promulgated has been clear to develop consumers' direct-purchasing electricity pilot, and gradually open the user's option from the beginning of large users. With the implementation of this program, the cross-subsidies that exist in the current sale price will lead to a series of problems in the electricity market reform process. Therefore, at this stage how to deal with cross-subsidies of sales price is an important issue to be solved in the process of China's power industry development.

\subsection{The Purpose and Significance of the Sales Price Cross-Subsidies Problem}

All along, the power industry has been regarded as welfare, deviating from its intrinsic value to provide users with low-cost power supply service. In order to compensate for the loss caused by the power supply enterprises to provide low-cost power supply services, governments have adopted different ways to give subsidies to the power enterprises. Among them, the cross-subsidies is one of the ways that the various regions of China generally adopted. Because sales price with cross subsidies was generally unaffected by the supply-demand relationship and the cost fluctuation, the price in the policy factor is much greater than its operating factors, resulting in an operating loss of power enterprises and the decrease of supply service levels, forming a vicious cycle of Loss-Cross-subsidize-Further loss. Gradually, the power companies cannot improve their economic fundamentally, making it difficult to be responsible for providing excellent power services.

Taking into account the actual situation that our country develops direct power-purchase pilot for large consumers, the existing sales price cross-subsidies may cause many problems. On the one hand, large customers enjoy cheap electricity services by direct power-purchase, and power companies lost cross-subsidies revenue once provided by the big users. At the same time, power companies still undertake its obligations to provide residential customers with universal electricity service, which may cause serious financial losses to grid companies. On the other hand, to some extent, the existing sales price cross-subsidies hindered the smooth progress of the reform of the electricity market. Reasonable solution to the problem of cross-subsidies sales price and improving the level of selling prices for various types of users, not only ensure healthy and sustainable development of the power companies, but also promote a smooth transition of China's power industry to the electricity market of free competition.

For such countries, China's rapid economic development, in the electricity market reform process, it is a complex issue that how to take into account all the factors, a rea- 
sonable solution to the sales price cross-subsidies for various types of users. Government implements sales price cross-subsidies, which has two purposes in the final analysis, one is the policy subsidies for economic development, the other is the universal service of the power. At the moment, the basic idea to solve this problem is to reduce or abolish unjustified sales price cross-subsidies, and gradually improve the sales price system for various users, prompting price levels more reasonable.

\subsection{The Study of the Sales Price Cross-Subsidies}

Cross-subsidy is a very important concept in the pricing theory, which reflects the relationship between revenues and costs attributable to a single commodity or commodity combinations. In the real price-making, cross-subsidy is often between the products and services, also among the different consumer groups, and electricity commodity pricing is no exception. With the rise of the reform of the electricity market boom, countries around the world have very high levels of concern for the sales price crosssubsidies, and scholars studied the sales price cross-subsidies from different angles. Paper [6] analyzed the relative ratio in the our current sales price system among residential, commercial, industrial users, and comparing with other countries, revealed the existence of serious cross-subsidies from industrial and commercial electricity to residential electricity prices. At present, domestic scholars mainly study the cross-subsidies faced by our country in the implementation of direct power-purchase pilot for large consumers. Paper [7] proposed a new program that big users enter the market to buy the electricity, the program stipulates that large users accessed to the trading center must bear some of the cost of cross-subsidies, and in accordance with certain criteria, cross-subsidies are apportioned according to each $\mathrm{kWh}$. Paper [8] proposed a phased solution of sales price cross-subsidies in the course of our country developing large users and power companies to deal directly. In addition, because there is a close connection between the sale price cross-subsidies and universal service, many scholars are conducting research in universal service with the sales price cross-subsidies. All in all, domestic scholars have reached a preliminary agreement in the sales price cross-subsidies, and have made some progress, but solutions and specific measures for the cross-subsidies has not been studied.

\subsection{The Ramsey Pricing Method}

Mathematical model of Ramsey pricing is expressed as follows. Suppose a public institution producing $\mathrm{n}$ types of products (or provide $\mathrm{n}$ types of customers with service), $i=1, \cdots, n$, and the demand for all kinds of products (or groups of users) are independent. Product consumption is $q=\left(q_{1}, \cdots, q_{n}\right)$, when the price vector is $p=\left(p_{1}, \cdots, p_{\mathrm{n}}\right)$, the demand function is $q_{i}=D_{i}\left(q_{1}, \cdots, q_{n}\right)$.

Enterprises Revenues: $R(q)=\sum_{i=1}^{n} p_{i} q_{i}$,

Cost Function: $C\left(q_{1}, \cdots, q_{n}\right)$,

Total Consumer Surplus: $S(q)=\int D_{i}\left(q_{i}, \cdots, q_{n}\right) \cdot d q-\sum_{i=1}^{n} p_{i} q_{i}$,

Producer Surplus: $R(q)-C\left(q_{1}, \cdots q_{n}\right)$, 
The Ramsey pricing problem is denoted as max. $\left\{S(q)+R(q)-C\left(q_{1}, \cdots q_{n}\right)\right\}$, S. t. $R(q)-C\left(q_{1}, \cdots q_{n}\right) \geq 0$.

The introduction of the Lagrange multiplier $\lambda$ makes the above maximization problem into:

$$
W=\int D_{i}\left(q_{1}, \cdots q_{n}\right) \cdot d q-C\left(q_{1}, \cdots q_{n}\right)+\lambda\left[R(q)-C\left(q_{1}, \cdots q_{n}\right)\right]
$$

The formula of $q_{i}$ were seeking a first-order partial derivatives,

$$
\begin{aligned}
& \frac{\partial W}{\partial q_{i}}=\left(p_{i}-M C_{i}\right)+\lambda\left(\frac{\partial p_{i}}{\partial q_{i}} q_{i}+p_{i}-M C_{i}\right)=0 \\
& \Rightarrow(1+\lambda)\left(p_{i}-M C_{i}\right)=-\lambda \frac{\partial p_{i}}{\partial q_{i}} q_{i} \\
& \Rightarrow \frac{p_{i}-M C_{i}}{p_{i}}=\frac{\lambda}{1+\lambda} \cdot \frac{1}{n_{i}}
\end{aligned}
$$

Among them, $\eta_{i}=\frac{\partial q_{i}}{\partial p_{i}} \cdot \frac{p_{i}}{q_{i}}$ is the price elasticity of demand of class I products (or class I user), if $R=\frac{\lambda}{1+\lambda}$ is denoted as the Ramsey index, then $p_{i}=M C_{i} /\left(1-R / \eta_{i}\right)$

The Equation shows that the price of each type of product (user) on the marginal cost of an addition $\left(p_{i}-M C_{i}\right) / p_{i}$ is inverse proportion to the price elasticity of the product demand, this is the famous rally rules. Ramsey pricing consider the impact of user demand price elasticity to product prices, greater elasticity of demand for the product, if the price is too high, it will cause a significant decrease in demand, thus resulting in the decrease of consumer surplus and the loss of social welfare. If the price elasticity of demand for products with a lower price, due to less demand for change, the impact on consumer surplus and social welfare is relatively small [9].

\subsection{The Analysis of the Ramsey Pricing Method}

In order to better solve the problem of sales price cross-subsidies, we can apply the Ramsey pricing theory to determine the level of sales price of classified users. Appropriate adjustments to the existing sales price level with reference to Ramsey pricing, to reduce or cancel the purpose of cross subsidies.

Ramsey pricing is a sub optimal pricing method which is determined by the marginal cost of the enterprise and the price elasticity of different kinds of users in order to ensure the balance of power grid enterprises. The power cost of the residents is higher than that of the industrial users, and the price elasticity of the residents' demand is less than that of the industrial users. In accordance with the Ramsey pricing theory, the sales price of the residents should be higher than the industrial customers, which is in line with the general situation of foreign residents in the electricity price is higher than the price of electricity [10].

The main steps of Ramsey pricing are shown in Figure 2. The difficulty lies in the determination of the marginal cost of power supply MCi and the price elasticity of demand for various types of users. 


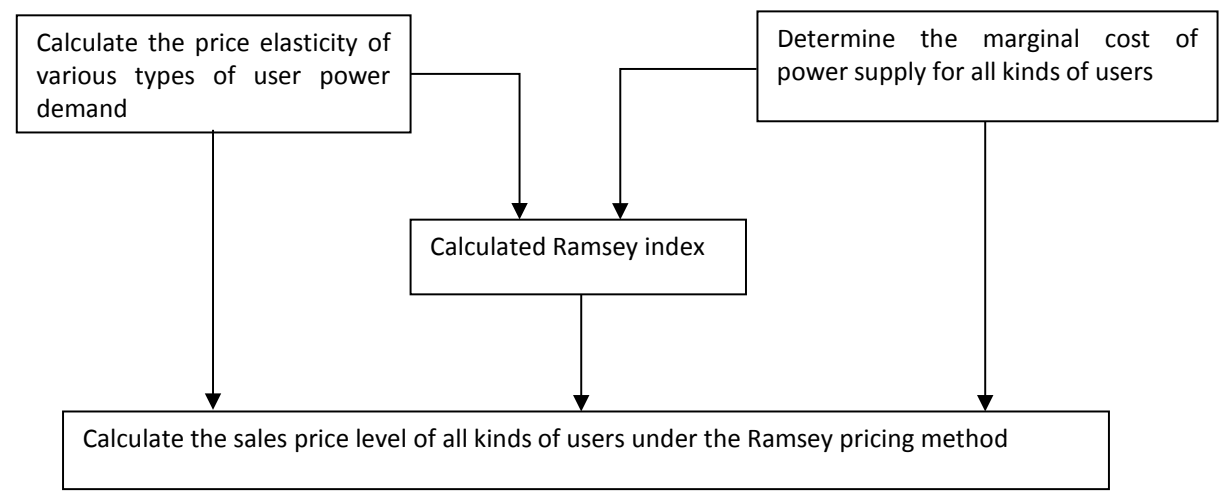

Figure 2. A outline of the Ramsey pricing method.

Under normal circumstances, the price elasticity of electricity demand increases with the increase of user power consumption. In accordance with the Ramsey pricing theory to determine the user's electricity price, industrial users demand price elasticity is higher and its power supply marginal cost is low, so the Ramsey tariff for industrial users should be low; in contrast, the demand price elasticity of residential users is small and its power supply marginal cost is higher, so it should be higher than the price of industrial electricity. To a certain extent, Ramsey price reduces the cross-subsidies in the past, and ensure the balance of corporate earnings under the premise to achieve the suboptimal goal of increasing social welfare, but it is not satisfactory in the social welfare distribution.

At present, China's current residential electricity price is lower than industrial tariffs. If you take Ramsey pricing method to determine the sales price of users, residential electricity prices will rise substantially, which is obviously unfair. The power of human life is an indispensable necessity, if substantial increase in residential electricity prices will lead to poor areas and low-income users not affording the high electricity bills, the impact of basic electricity needs of these users daily.

To solve the above problem, consider the lifeline tariff for residential users combined with Ramsey pricing, determine the lifeline of residential users per capita electricity consumption standards, within this standard residential electricity demand have greater rigidity. When residents of the user is within this standard, according to the lifeline electricity tariff to be settled; if residents lifeline electricity consumption exceeds the standard, the standard price of electricity by lifeline settlement, the excess electricity tariff by Ramsey settlement. This approach not only ensures the poor areas, low-income residents basic daily demand for electricity, but also encourages users to conserve electricity, to achieve optimal allocation of resources.

In the total welfare function, different users can set different welfare weights, and their mathematical expression is as follow: $\left(p_{i}-M C_{i}\right) / p_{i}=\lambda / \eta_{i}\left(\alpha_{i}+\lambda\right), \alpha_{i}$ is social welfare weight factor. Government related departments can set or adjust the value $\alpha_{i}$ of residents, industry and other users, so as to achieve a reasonable adjustment of different kinds of user sales price, and to meet the purpose of different types of users of electricity demand. 


\section{Conclusions}

From the introduction of the classic example of six people, we found that there is a necessity that there must be 3 people knowing each other or not knowing each other. In the same way, we can find 9 people are bound to meet that either 3 people not knowing each other or 4 people knowing each other. From the above, we found some particularity of the number, and the number is called Ramsey number, but Ramsey number can't be obtained with the right formula so far. The charm of Ramsey number lies in its uncertainty and practicality, so a large number of scholars will be interested in it. I believe that in the near future we will come up with more Ramsey number.

Finally, we apply the Ramsey number to real life, and introduce the Ramsey pricing method. Ramsey pricing theory focuses on solving the issues of the sales price crosssubsidies, but the theory still involves little in the field of electricity pricing, whose rationality and practicability of the pricing should be further studied and tested; on the other hand, because the solution to the sale price cross-subsidies in practice might lead to the problems in different development stages of China's electric power industry, such as the difficulty of the low income residents, the implementation of the power universal service and so on, we need further study.

\section{References}

[1] Zhao, W.F. (2010) The Construction Method and Random Graph of Ramsey Theory. Master's Degree Thesis, National University of Defense Technology, Changsha.

[2] Bao, Q.Q. (2009) Some Generalized Ramsey Number Calculation. Master's Degree Thesis, Huazhong University of Science and Technology, Wuhan.

[3] Li, T. (2006) Ramsey Number on the Even-numbered Rounds. Master's Degree Thesis, Dalian University of Technology, Dalian.

[4] Bai, L.F. (2004) Research on Some Problems in Generalized Ramsey Numbers. Master's Degree Thesis, HoHai University, Nanjing.

[5] Xu, X.D. (2002) Classical Ramsey Theory and Its Applications. Master's Degree Thesis, National University of Defense Technology, Changsha.

[6] Que, G.H. (2003) Cross-Subsidization, International Comparison and Reform. Electric Power Technologic Economic, No. 2, 24-27.

[7] Zeng, M., Yu, J.R. and Wang, H. (2007) Research on a New Large User Access to Electricity Market Electricity Purchasing. North China Electric Power Technology, No. 4, 26-29.

[8] State Electricity Regulatory Commission, the State Grid Corporation, State Grid Beijing Economic and Technology Research Institute (2007) Research on Direct Trading between Large Users and Power Companies. Beijing Economic Research Institute State Grid.

[9] Bigerna, S. and Bollino, C.A. (2016) Ramsey Prices in the Italian Electricity Market. Energy Policy, 88, 603-612. http://dx.doi.org/10.1016/j.enpol.2015.06.037

[10] Bigerna, S. and Bollino, C.A. (2016) Optimal Price Design in the Wholesale Electricity Market. Energy Journal, 37, No. SI2. http://dx.doi.org/10.5547/01956574.37.si2.sbig 
Submit or recommend next manuscript to SCIRP and we will provide best service for you:

Accepting pre-submission inquiries through Email, Facebook, LinkedIn, Twitter, etc. A wide selection of journals (inclusive of 9 subjects, more than 200 journals)

Providing 24-hour high-quality service

User-friendly online submission system

Fair and swift peer-review system

Efficient typesetting and proofreading procedure

Display of the result of downloads and visits, as well as the number of cited articles

Maximum dissemination of your research work

Submit your manuscript at: http://papersubmission.scirp.org/

Or contact jec@scirp.org 